John R. Ledsome MD DSc, Colm Cole MD FRCPC, Jeannie M. Sharp-Kehl RN

\title{
Somatosensory evoked potentials during hypoxia and hypocapnia in conscious humans
}

Purpose: The objective of the study was to evaluate the effects of moderate hypoxia and hypocapnia on the latency and amplitude of cortical somatosensory evoked potentials (SSEPs) in conscious human subjects.

Methods: In ten volunteers the amplitude and latency of the cortical somatosensory evoked potentials were recorded during stimulation of the left posterior tibial nerve. Measurements of SSEPS and respiratory variables were made breathing ambient air, air containing a reduced oxygen percentage $\left(17 \% \mathrm{O}_{2}, 14 \% \mathrm{O}_{2}(n=6)\right.$ or $\left.11 \% \mathrm{O}_{2}(n=10)\right)$, and again during voluntary hyperventilation breathing ambient air $\left(\mathrm{PETCO}_{2}\right.$ $=20 \mathrm{mmHg}, n=10$ ).

Results: Hypoxia $\left(11 \% \mathrm{O}_{2}\right)$ caused mild stimulation of ventilation $(P<0.05)$ but had no effects on the latency or amplitude of the SSEP. Lesser degrees of hypoxia had no effects. Hyperventilation caused a small (2-4\%) decrease) in the latency of the SSEP and an increase in the amplitude of the $\operatorname{SSEP}(P<0.05)$.

Conclusions: These findings in conscious subjects were consistent with previous observations in anaesthetized humans and anaesthetized dogs and show that the decrease in latency of the SSEP associated with hypocapnia is not due to changes in the depth of anaesthesia. These effects of hypocapnia may

\section{Key words}

HYPOCAPNIA:

HYPOXIA:

MONITORING: evoked potentials.

From the Departments of Physiology and Anaesthesia,

University of British Columbia and Microgravity Life

Sciences Research Unit, Vancouver Hospital, Vancouver, BC,

CanadaV6T $1 Z 3$.

This work was supported by the Canadian Space Agency.

Address correspondence to: Dr. J.R. Ledsome, Department of Physiology, 2146, Health Sciences Mall, Vancouver, BC,

Canada V6T 1 Z3.

Phone: 604-822-2318. Fax: 604-822-6048

E-MAIL: jledsome@unixg.ubc.ca

Accepted for publication June 1, 1996. contribute to small variations in the latency of the SSEP when monitoring is performed during surgery, but are unlikely to be large enough to be of clinical concern.

Objectif: Évaluer les effets de l'hypoxie et de l'hypocapnie modérées sur la latence et l'amplitude des potentiels somatosensoriels corticaux évoqués (PSSE) chez des humains conscients.

Méthodes: Chez dix volontaires, l'amplitude et la latence des potentiels somatosensoriels corticaux évoqués ont été enregistré pendant la stimulation du nerf tibial postérieur gauche. La mesure des PSSE et des variables respiratoires a été réalisée en air ambiant, en air avec un pourcentage réduit d'oxygène $\left(17 \% \mathrm{O}_{2}, 14 \% \mathrm{O}_{2}(n=6)\right.$ ou $\left.11 \% \mathrm{O}_{2}(n=10)\right)$ et par la suite en air ambiant pendant l'hyperventilation volontaire $\left(\mathrm{PETCO}_{2}=20 \mathrm{mmHg}, n=10\right)$.

Résultats: L'hypoxie $\left(11 \% \mathrm{O}_{2}\right)$ a provoqué une légère stimulation de la ventilation $(P<0,05)$ mais n'a pas eu d'effet sur la latence et l'amplitude des PSSE. Les degrés moindres d'hypoxie n'ont pas eu d'effet. L'hyperventilation a provoqué une petite diminution (2-4\%) de latence et une augmentation de l'amplitude des PSSE $(P<0,05)$.

Conclusion: Ces constatations chez des sujets conscients sont cohérentes avec les observations antérieures notées chez des sujets conscients et chez des chiens anesthésiés et montrent que la baisse de latence des PSSE n'est pas causée par des changements de profondeur d'anesthésie. Ces effets de l'hypocapnie peuvent contribuer à de petites variations de la latence des PSSE décelées par le monitorage en chirurgie, mais ils est peu probable qu'elles soient assez importantes pour inquiéter.

Monitoring of somatosensory evoked potentials (SSEPs) has been used to avoid adverse neurological outcomes resulting from compromise of the spinal cord during surgery.' Somatosensory evoked potentials have also been widely used in the evaluation of patients with acute spinal cord injury. ${ }^{2}$ They have been studied in normal ${ }^{3}$ and abnormal ${ }^{4}$ clinical situations and also in animal 
models including those of spinal traction. ${ }^{5}$ Many factors affect the amplitude, latency and quality of the SSEPs recorded during anaesthesia including temperature, choice of anaesthetic agent, depth of anaesthesia and electrical interference. Severe hypoxia leads to a decrease in the amplitude of the SSEP. ${ }^{6}$ Hypocapnia $\left(\mathrm{PETCO}_{2}=20 \mathrm{mmHg}\right)$ has been shown to result in a decreased latency of cortical SSEPs in anaesthetized $\operatorname{dogs}^{7}$ and also in anaesthetized humans ${ }^{8}$ but the role of changes in the depth of anaesthesia was not ruled out as a mechanism for the change. Changes in ventilation in patients being monitored during surgery might cause changes in the latency of the SSEPs. The objective of this study was to determine whether moderate hypoxia or hypocapnia altered the latency of SSEPs in conscious human subjects thus eliminating any influence of changes in depth of anaesthesia on the latency.

\section{Methods}

Somatosensory evoked potentials were recorded in 10 healthy, normal volunteers (five male, five female) aged between 20 and $60 \mathrm{yr}$. The study was approved by the Clinical Screening Committee for Research and other Studies Involving Human Subjects of the University of British Columbia. Somatosensory evoked potentials were recorded using a portable, four channel stimulator and signal averaging system (Quantum 84, Cadwell Labs., Kennewick, WA). Constant current, square-wave stimuli were delivered to the posterior tibial nerve at the ankle (duration $0.1 \mathrm{msec}, 6.75 \mathrm{~Hz}, 12-25 \mathrm{~mA}$ ) using surface electrodes (Medi-trace disposable pediatric electrodes, Graphic Controls, Buffalo,. NY) placed below the medial malleolus and on the medial surface of the left foot. The electrodes were placed approximately 4 $\mathrm{cm}$ apart and the proximal electrode was the cathode. The stimulus strength was adjusted to that which caused a just-detectable motor response in the foot (toe twitch). Evoked potentials were recorded using surface electrodes (Diaphoretic Monitoring Electrodes, 3M, Canada Inc., London, Ontario) which were placed over the popliteal fossa and at the vertex. In four of the 10 subjects intradermal needle electrodes were used at the vertex. Reference electrodes were placed at the medial side of the knee and on the forehead and a ground was placed on the mid-calf. The electrode positions were not standard and were chosen because we wished to make comparison with results obtained in a previous study in which constraints were imposed by the difficulty of making measurements in a microgravity environment. ${ }^{9}$ The inter-electrode impedance was always $<3 \mathrm{k} \Omega$. Recordings consisted of the average of 400 stimuli; filters were set at 300 and $100 \mathrm{~Hz}$ for the popliteal and at 500 and $10 \mathrm{~Hz}$ for the cortical recordings. This band-pass

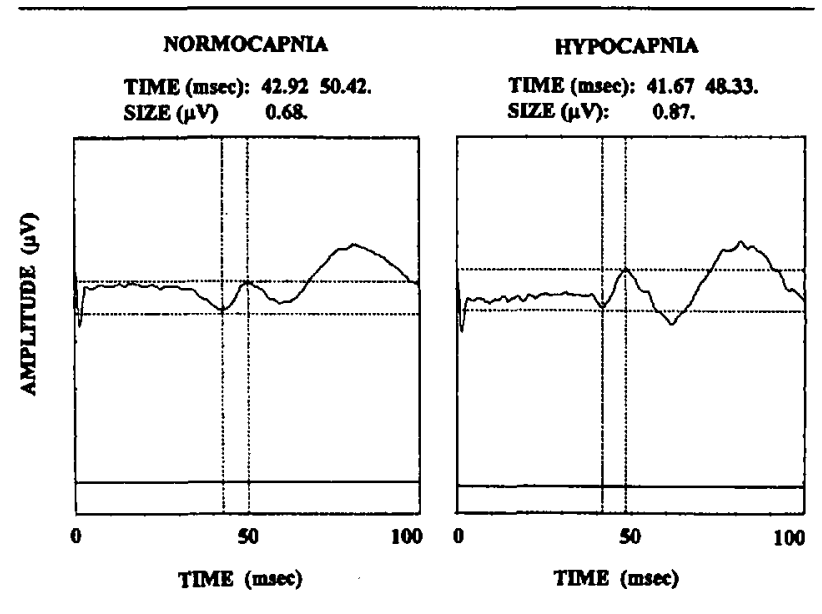

FIGURE Example of cortical SSEPs in one subject. Each trace is the average of four sets of 400 stimuli. On the left during normal breathing (normocapnia) and on the right during hyperventilation (hypocapnia). Electronic cursors have been placed on the peaks of the $P_{40}$ and $N_{50}$ waves to measure latencies and the amplitude between $P_{40}$ and $\mathrm{N}_{50}$. The values read by the cursors are shown above the figures.

was somewhat less than that usually used clinically but was recommended by the manufacturers of the instrument and allowed recording in less than ideal conditions of electrical interference. At least five sets of recordings were obtained in each condition during the protocol and were stored on 3.5 inch floppy disks for subsequent measurement of latency using electronic cursors. Measurements were made of the latency of the popliteal evoked potential and of the early cortical evoked potentials which were designated $\mathrm{P}_{40}, \mathrm{~N}_{50}$ and $\mathrm{P}_{60}$ (Figure). Amplitudes were measured between the peaks of $\mathbf{P}_{40}$ and $\mathrm{N}_{50}$ and between $\mathrm{N}_{50}$ and $\mathrm{P}_{60}$. In some cases, latencies and amplitudes were measured after electronically averaging the signals from four sets of 400 stimuli. The average obtained in this way did not differ from that reached by averaging the results of the individual sets.

Somatosensory evoked potentials were recorded in each of 10 supine subjects who breathed through an airtight face mask (Warren E. Collins, Millis, MA). In the first six subjects, the inspiratory port of the face mask was supplied with one of four gas mixtures: room air $\left(21 \% \mathrm{O}_{2}, 79 \% \mathrm{~N}_{2}\right) ; 17 \% \mathrm{O}_{2}, 83 \% \mathrm{~N}_{2} ; 14 \% \mathrm{O}_{2}, 86 \% \mathrm{~N}_{2}$ and $11 \% \mathrm{O}_{2}, 89 \% \mathrm{~N}_{2}$. The subject first breathed room air after which the other three gas mixtures were breathed in random order; finally room air was breathed again. In the last four subjects the tests of $17 \% \mathrm{O}_{2}$ and $14 \% \mathrm{O}_{2}$ were omitted because these mixtures were having no effect on any of the measured variables. Each gas mixture was breathed for $10 \mathrm{~min}$ before recording of SSEPs began. Five sets of 400 stimuli were delivered while breathing each gas mixture. Ventilatory variables 
TABLE Effects of hypoxia $\left(11.1 \% \mathrm{O}_{2}\right)$ and hyperventilation, in 10 subjects, on respiratory variables and the latency of the cortical SSEP $\left(\mathrm{N}_{50}\right)$

\begin{tabular}{lcccc}
\hline \multicolumn{3}{c}{ Spontaneous breathing } & & Hypenventilation \\
\hline Inspired $\mathrm{O}_{2} \%$ & $20.9 \% \mathrm{O}_{2}$ & $11.1 \% \mathrm{O}_{2}$ & $20.9 \% \mathrm{O}_{2}$ & $20.9 \% \mathrm{O}_{2}$ \\
$\mathrm{VE} \mathrm{L} \cdot \mathrm{min}^{-1}$ & $7.4 \pm 0.2$ & $8.5 \pm 0.5^{*}$ & $7.3 \pm 0.4$ & $23.4 \pm 6.5^{*}$ \\
$\mathrm{VT} \mathrm{ml}$ & $594 \pm 71$ & $666 \pm 80$ & $558 \pm 86$ & $1058 \pm 149^{*}$ \\
$\mathrm{f}$ breaths $\cdot \mathrm{min}^{-1}$ & $13.8 \pm 1.4$ & $14.6 \pm 1.7$ & $14.9 \pm 1.3$ & $24.8 \pm 2.6^{*}$ \\
$\mathrm{PETCO}_{2} \mathrm{mmHg}$ & $35.7 \pm 1$ & $32.8 \pm 1.1$ & $33.1 \pm 1$ & $19.7 \pm 1^{*}$ \\
$\mathrm{PETO}_{2} \mathrm{mmHg}$ & $111 \pm 2$ & $48.4 \pm 1.2^{*}$ & $112 \pm 2$ & $135 \pm 1.5^{*}$ \\
Latency $\left(\mathrm{N}_{50}, \mathrm{msec}\right)$ & $49.87 \pm 0.8$ & $49.0 \pm 0.9$ & $49.80 \pm 0.8$ & $47.96 \pm 0.7^{*}$ \\
\hline
\end{tabular}

$V E$, minute ventilation; $V T$, tidal volume; $f$, breathing frequency; $P E T C C_{2}$, end-tidal partial pressure of $\mathrm{CO}_{2}$; $\mathrm{PETO}_{2}$, end-tidal partial pressure of oxygen. Values are means SEM, $n=10$.

*Significantly different $(P<0.05)$ from average of values during normal ventilation with room air $\left(20.9 \% \mathrm{O}_{2}\right)$.

were measured continuously using a Beckman Metabolic Cart (Beckman Inst. Co., Missisuaga, Ontario.) that provided a record of minute ventilation, tidal volume, respiratory rate, $\mathrm{PETCO}$ and $\mathrm{PETO}_{2}$ averaged over each $90 \mathrm{sec}$. The values reported for the respiratory variables were the average of the final three periods, recorded at the same time as the SSEPs. After completion of this protocol each subject, while breathing ambient air, was asked to increase their tidal volume and respiratory rate voluntarily to about double the resting values and was subsequently instructed to make adjustments to achieve a measured $\mathrm{PETCO}_{2}$ of about $20 \mathrm{mmHg}$. Recording of SSEPs began after 10 min of hyperventilation.

\section{Statistical analysis}

An average value for latencies of the SSEPs for the five tests with each gas mixture and during hyperventilation was calculated. In six subjects the effects breathing $17 \%$ and $14 \%$ oxygen on the latency of the SSEPs and the respiratory variables were compared with the effects of breathing room air using analysis of variance with a randomized block design (NCSS, Kaysville, OH). The effects of breathing $11 \% \quad \mathrm{O}_{2}$ and hyperventilation (breathing ambient air) were analysed in the total of ten subjects using the same statistical tests. When a significant change was indicated the level of probability was assessed using a Newman-Keuls post-hoc test. A probability of $P<0.05$ was considered significant for all comparisons.

\section{Results}

\section{Effects of hypoxia}

In six subjects, breathing gas mixtures of $17.2 \%, 14.2 \%$ and $11.1 \%$ oxygen changed end-tidal oxygen partial pressure to $82.3 \pm 3.8 \mathrm{mmHg}, 63.1 \pm 1.2 \mathrm{mmHg}$ and $46.4 \pm 1.1 \mathrm{mmHg}$, close to the values of 80,60 and 40
$\mathrm{mmHg}$ that were predicted from the alveolar air equation, assuming an alveolar arterial oxygen difference of $8 \mathrm{mmHg}$. Although there was a small increase in minute ventilation with the lowest oxygen concentration this change failed to reach statistical significance and there were no changes in tidal volume, respiratory rate and $\mathrm{PETCO}_{2}$. There were no changes in the latency or amplitude of the popliteal or cortical SEEPs associated with breathing gas mixtures with reduced oxygen concentration.

Because it seemed that statistical significance in respiratory variables would be achieved with an increased number of subjects, a further four subjects breathed only room air and $11.1 \%$ oxygen and the data from all 10 subjects were pooled (Table). Hypoxia $\left(\mathrm{PETO}_{2}-48.4 \pm\right.$ $1.2 \mathrm{mmHg}$ ) was shown to be accompanied by a small but significant increase in minute ventilation; other variables, including the latency and amplitude of the SSEPS remained unchanged.

\section{Effects of hyperventilation}

Voluntary hyperventilation resulted in an approximately four times increase in minute ventilation, $\mathrm{PETCO}_{2}$ decreased to $20 \mathrm{mmHg}$ and $\mathrm{PETO}_{2}$ increased to 135 $\mathrm{mmHg}$. All 10 subjects were able to maintain this state for approximately 15 min during the last five minutes of which the measurements were made. One subject, whose end-tidal $\mathrm{PCO}_{2}$ decreased to $17 \mathrm{mmHg}$, showed mild clinical signs of tetany at the end of the period of hyperventilation which resolved shortly after hyperventilation was stopped. As expected, all respiratory variables changed during hyperventilation. The latency of the cortical SSEPs was reduced $(P<0.05)$ during hyperventilation. Values for the $\mathrm{P}_{50}$ wave are given in the Table; the latency of the $P_{40}$ wave was $43.0 \pm 1.5 \mathrm{msec}$ at rest and $41.9 \pm 1.2$ during hyperventilation and the latency of the $P_{60}$ wave was $61.0 \pm 0.8$ at rest and $59.5 \pm$ 0.8 during hyperventilation. An example of the cortical 
SSEP in one subject breathing normally and during hyperventilation is shown in the Figure. The amplitudes of the $\mathrm{P}_{40}$ to $\mathrm{N}_{50}(0.76 \pm 0.13$ to $1.3 \pm 0.16 \mathrm{~V})$ and of the $N_{50}$ to $P_{60}(1.07 \pm 0.28$ to $1.58 \pm 0.22 \mathrm{~V})$ waves were increased during hyperventilation. The signals were somewhat noisier during hyperventilation presumably due to the increased muscular movements associated with the increased respiratory activity. However, there was no difficulty in identifying the normal waveforms. The latency of the popliteal SSEP measured in six subjects was $9.76 \pm 0.32 \mathrm{msec}$ breathing normally and 9.48 $\pm 0.42 \mathrm{msec}$ during hyperventilation. This difference was not statistically significant; in the other four subjects the popliteal SSEP could not be separated from the stimulus artifact.

\section{Discussion}

The standard deviation of the latency of the $\mathrm{N}_{50}$ wave reported in previous studies has been of the order of $5-7 \%$ of the latency even after accounting for differences in height ${ }^{10}$ and age ${ }^{3}$ of the individuals. This variability mainly reflects biological differences between individuals in the group and we have recently shown that the variability of repeated observations in the same individual is considerably less and is of the order of $1.5 \%$ of the latency. ${ }^{9}$ This means that it should be possible to distinguish changes in the latency of the SSEP of the order of 2-3 msec for the $N_{50}$ wave, with repeated measurements in individual subjects. The current experiments were designed to allow comparison of latencies of the SSEP within the same subject in response to acute changes in respiratory variables.

\section{Effects of hypoxia}

The ventilatory response to moderate hypoxia in human subjects is limited partly by the response characteristics of the peripheral chemoreceptors to hypoxia ${ }^{1 !}$ and by the fact that any increase in ventilation causes hypocapnia which opposes the stimulatory effect of the hypoxia. It was only with the lowest oxygen concentration of $11.1 \% \mathrm{O}_{2}$ that an increase in minute ventilation was observed but this increase in ventilation was not sufficient to cause a decrease in $\operatorname{PETCO}_{2}$. This degree of hypoxia which produced a $\mathrm{PETO}_{2}$ of $48 \mathrm{mmHg}$ (Table) did not cause changes in the latency or amplitude of the SSEP. The small changes in ventilation observed in response to hypoxia in the present study were consistent with the previous observations of Dripps and Comroe. ${ }^{12}$ Progressive, severe hypoxia in dogs caused an increase in the latency of the cortical SSEP and a proportionately greater decrease in the amplitude of the SSEP. ${ }^{13}$ However, less severe hypoxia caused by administration of $10 \%$ oxygen, which decreased $\mathrm{PaO}_{2}$ to $31 \mathrm{mmHg}$, did not cause any changes in cerebral oxygen consumption or in the amplitude or latency of the SSEP in these dogs.

\section{Effects of hyperventilation}

Acute hypocapnia $\left(\mathrm{PETCO}_{2}=20.6 \mathrm{mmHg}\right)$ has previously been shown to cause a small decrease in the latency of the median nerve SSEP in anaesthetized human subjects. ${ }^{8}$ The decrease in the latency of the median nerve SSEP was shown to be $3.7 \%$ of the latency at normocapnia. Our results, using stimulation of the posterior tibial nerve, show a remarkable similarity to the previous results, that is a change of $3.7 \%$ of the latency of the $\mathrm{P}_{50}$ wave at normocapnia. Somewhat smaller $(2 \%)$ but directionally similar changes were found in anaesthetized dogs at a $\mathrm{PaCO}_{2}$ of $20 \mathrm{mmHg}{ }^{.}$No consistent changes in the amplitude of the SSEP were reported in any of these studies. Changes in the latency of the popliteal evoked potential were directionally similar but did not reach statistical significance.

The question was raised by both groups of authors ${ }^{7,8}$ as to whether the changes in the latency could have been due to changes in the level of anaesthesia provoked by hyperventilation. Repeating the tests in conscious human subjects avoids any concern about changing anaesthetic levels but introduces other variables related to the change in attention of the subject and the increased voluntary movements of the respiratory muscles. The shortest latency components of the cortical SSEP are thought to arise in the primary somatosensory area of the corte ${ }^{2}$ whereas the later components probably arise in the secondary sensory area and the association areas of the cortex. The short latency components that we have studied are believed to be less affected by other cortical activity than the later components. It seems unlikely that the decrease in latency observed can be attributed directly to increased attention or an increase in voluntary muscle activity. There is marked attenuation of the initial cortical potentials produced by stimulation of group I muscle afferents from the lower limb during walking. ${ }^{14}$ Standing was also associated with a decline in the amplitude of the earliest components of the posterior-tibial cortical potential. ${ }^{15}$ In neither case were the latencies of the early components affected. In previous studies ${ }^{7,8}$ using mechanical ventilation and anaesthesia the amplitudes of the cortical SSEPs were unaffected by hyperventilation. In our experiments with voluntary hyperventilation we found a small increase in the amplitude of the $P_{40}$ to $\mathrm{N}_{50}$ wave and the $N_{50}$ to $P_{60}$ wave. Thus, the early components of the cortical SSEP were not attenuated by increased activity of the respiratory muscles during hyperventilation. The importance of the changes in amplitude is unclear. 
Our findings in conscious human subjects show that the decrease in the latency of the SSEP associated with hypocapnia is not due to changes in the depth of anaesthesia. It seems more likely that the decrease in the latency of the SSEP is due to the respiratory alkalosis induced by hyperventilation. Alkalosis is well known to be associated with an increase in the excitability of neurons in the central nervous system and the peripheral nerves. The increase in excitability can probably be attributed to a decrease in the ionized calcium concentration ${ }^{16}$ in the extracellular fluid but direct effects of $\mathrm{pH}$ and $\mathrm{PCO}_{2}$ cannot be excluded. The role of the respiratory alkalosis is emphasized by the fact that one of our subjects showed the clinical signs of tetany during hyperventilation.

The changes in the latency and amplitude of the SSEP during hyperventilation were small $(2-4 \%$ of the latency) and although they could contribute to variations in latency during monitoring, are probably not of serious concern. A moderate degree of arterial hypoxaemia was not found to produce any changes in the latency of the SSEP.

\section{References}

1 Loder RT, Thomson GJ, LaMont RL. Spinal cord monitoring in patients with nonidiopathic spinal deformities using somatosensory evoked potentials. Spine 1991; 16: 1359-64.

2 Grundy $B L$, Friedman $W$. Electrophysiological evaluation of the patient with acute spinal cord injury. Crit Care Clin 1987; 3: 519-48.

3 Verroust J, Blinowska A, Vilfrit R, Couperie D, Malapert $D$, Perrier $M$. Somatosensory evoked potentials from posterior tibial nerve: normative data. Electromyogr Clin Neurophysiol 1989; 29: 299-303.

4 Notermans SLH, Vlek NMTh. Cortical and spinal somatosensory evoked potentials in patients suffering from lumbosacral disc prolapse. Electromyogr Clin Neurophysiol 1988; 28: 33-7.

5 Salzman SK, Dabney KW, Mendez AA, et al. The somatosensory evoked potential predicts neurologic deficits and serotonergic pathochemistry after spinal distraction injury in experimental scoliosis. J Neurotrauma 1988; 5: 173-86.

6 Eldridge PR, Hope DT, Yeoman PM, et al. Somatosensory evoked potentials in intracranial hypertension: analysis of the effects of hypoxia. J Neurosurg 1991; 75 : 108-14.

7 Gravenstein MA, Sasse F, Hogan $K$. Effects of hypocapnia on canine spinal, subcortical, and cortical somatosensory-evoked potentials during isoflurane anesthesia. J Clin Monit 1992; 8: 126-30.

8 Schubert A, Drummond JC. The effect of acute hypocap- nia on human median nerve somatosensory evoked responses. Anesth Analg 1986; 65: 240-4.

9 Ledsome JR, Cole C, Gagnon F, Susak L, Wing P. Long term stability of somatosensory evoked potentials and the effects of microgravity. Aviat Space Environ Med 1995; 66: 641-4.

10 Alonso JA, Hadju M, Gonzalez EG, Michelsen C. Semedei R. Cortical somatosensory evoked potentials: effects of positional changes. Arch Phys Med Rehabil 1989; 70:194-8.

11 Hornbein TF. The relation between stimulus to chemoreceptors and their response. In: Torrance RW (Ed.). Arterial Chemoreceptors. Oxford: Blackwell Scientific Publications, 1968: 65-78.

12 Dripps RD, Comroe JH Jr. The effect of the inhalation of high and low oxygen concentrations on respiration, pulse rate, ballistocardiogram and arterial oxygen saturation (oximeter) of normal individuals. Am J Physiol 1947; 149 : 277-91.

13 McPherson RW, Zeger S, Traystman RJ. Relationship of somatosensory evoked potentials and cerebral oxygen consumption during hypoxic hypoxia in dogs. Stroke 1986; 17: $30-6$.

14 Dietz V, Quintern J, Berger W. Afferent control of human stance and gait: evidence for blocking of group 1 afferents during gait. Exp Brain Res 1985; 61: 153-63.

15 Applegate C, Gandevia SC, Burke D. Changes in muscle and cutaneous cerebral potentials during standing. Exp Brain Res 1988;71:183-8.

16 Frankenhaeuser B, Hodgkin AL. The action of calcium on the electrical properties of squid axons. J Physiol (Lond) 1957; 137: 218-44. 